\title{
Wind tunnel study of axial force variation in guys of flexible mast models
}

\author{
J. Bęc ${ }^{1}$, E. Błazik-Borowa ${ }^{1}$ and T. Lipecki ${ }^{1}$ \\ ${ }^{1}$ Lublin University of Technology, Department of Structure Mechanics, Nadbystrzycka 38d St., 20 -618 Lublin, Poland
}

\begin{abstract}
Measurements of the axial force variation in guys of mast model subjected to wind load of three different wind structures are presented in the paper. The measurements have been carried out in the wind tunnel of Wind Engineering Laboratory at Cracow University of Techn ology. The subjects of the research are two guyed masts of triangular and square shaft cross-sections. Mean values of forces and standard deviations as functions of wind parameters and wind attack angle have been calculated. Significant influence of wind structure on the forces in guys has been confirmed as the result. Additionally there has been noticed possibility of mast vibrations at critical velocities.
\end{abstract}

\section{Introduction}

Guyed masts are used as supporting structures for radio and television antennas and mobile phone transmitters. These media are still being developed and therefore we can expect more and more masts to be built. Problems of loads evaluation for guyed masts, static and dynamic analyses of such structures, as well as design methods are still up-to-date scientific problems.

The paper presents a study of axial force variation in guys of flexible mast models under the wind load, and indicates that the structure of the wind has significant effect on their values. This issue and others (see [1, 2, 3]) related to the wind action on masts, are very important for designers of such structures.

\section{Description of the research methods}

The measurements were carried out in the wind tunnel of Wind Engineering Laboratory at Cracow University of Technology. The research was conducted on mast models with a height of $1.0 \mathrm{~m}$, with two levels of guys and two types of shaft cross-sections: square and triangular (Fig.1). The models of masts were rotated during the tests, for the mast of square cross-section, the following angles of wind attack $\alpha$ (the angle between the plane formed by the guy and shaft axis, and the vertical windward plane) were used: $0^{\circ}, 45^{\circ}, 90^{\circ}, 135^{\circ}$ and $180^{\circ}$, while for the mast of triangular cross-section the $\alpha$ angles were: $0^{\circ}, 30^{\circ}, 60^{\circ}, 90^{\circ}, 120^{\circ}, 150^{\circ}$ and $180^{\circ}$.

The measurements were performed at 16 wind speed levels equally spread in the range from $0 \mathrm{~m} / \mathrm{s}$ to 20 $\mathrm{m} / \mathrm{s}$. Three wind structures, described in detail in $[3,4]$, were used as the inflow condition (Fig. 2). The measurements of forces in guys were made with use of
HBM Hottinger S2/100 force transducer with the range of measured forces: $-100 \div+100 \mathrm{~N}$.

a)

b)
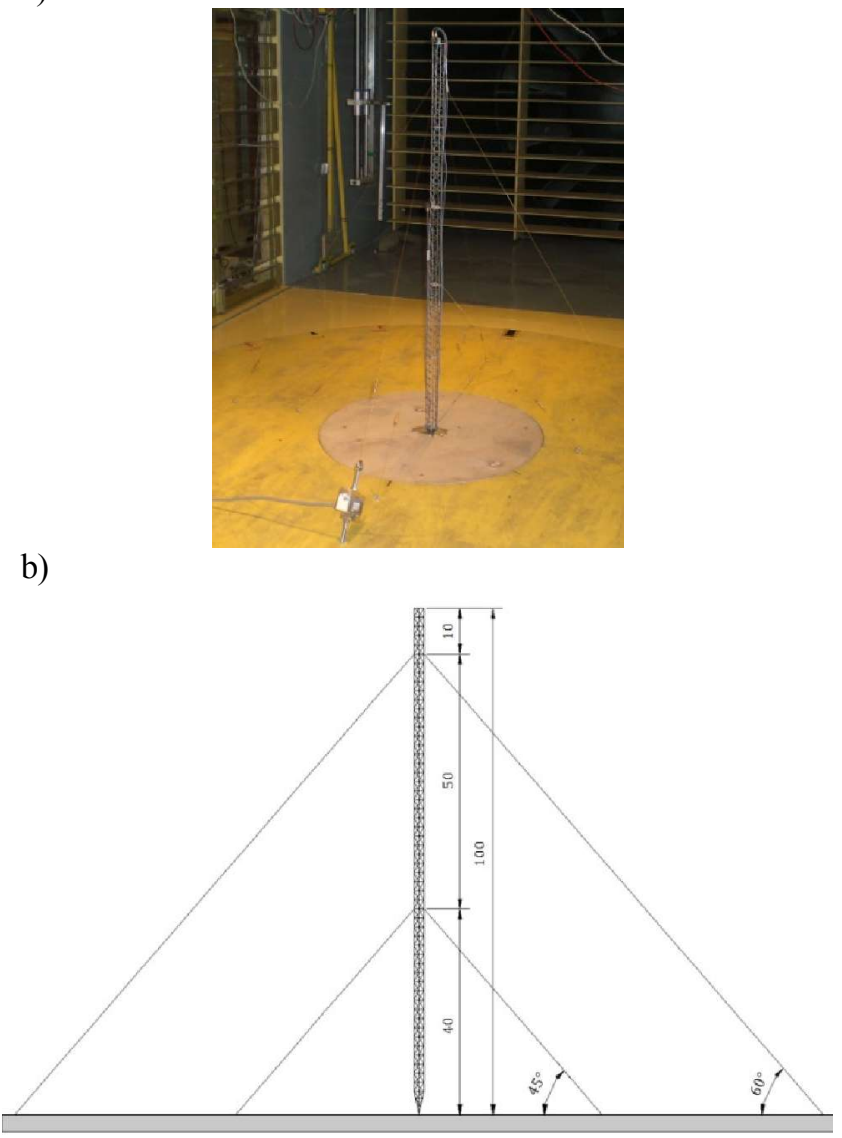

Fig. 1. Geometry: a) view of the model in the wind tunnel, b) model dimensions $[\mathrm{cm}]$. 
a)

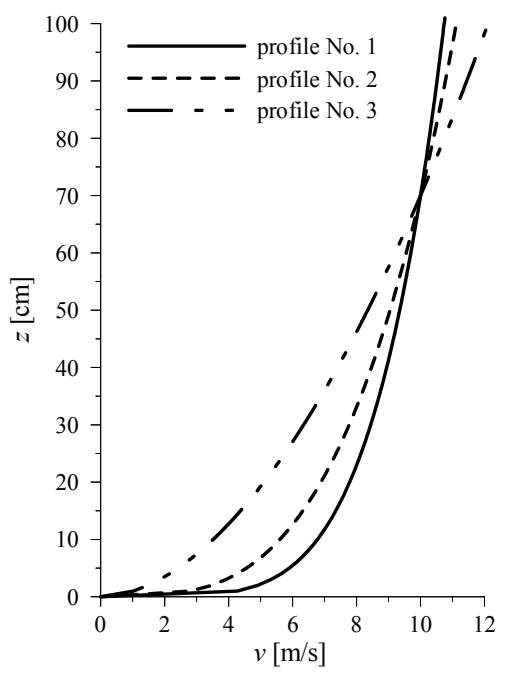

b)

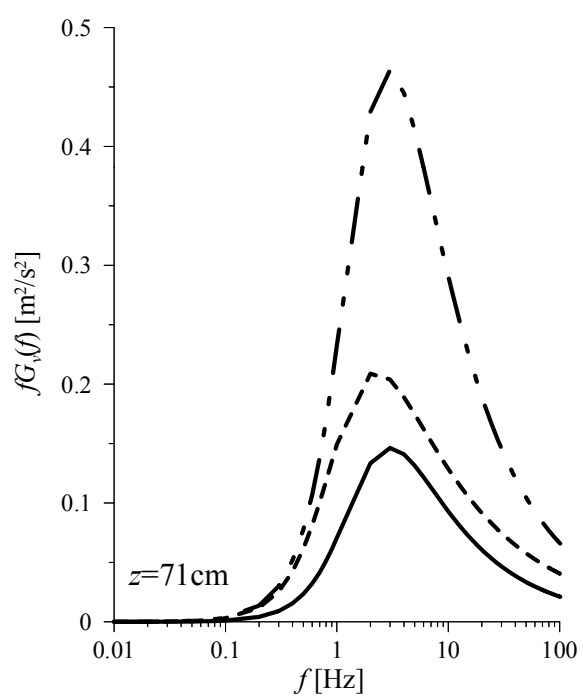

Fig. 2. Wind parameters: a) mean wind speed profile, b) power spectral density of wind; where $v$ - velocity, $f$ - frequency, $G$ power spectral density, $z$ - height.

\section{Results}

Time series of the axial forces in guys caused by the wind were obtained as the result of the measurements. Exemplary measurement results for the triangular shaft mast at $v=10 \mathrm{~m} / \mathrm{s}$ have been shown in Fig. 3. The presented results do not show the total value of axial force but only the difference between the tensional force value $F_{t}$ and the initial force in a guy $F_{o}$. The positive value $\left(F=F_{o}-F_{t}>0\right)$ means that the force is diminished, while the negative value $\left(F=F_{o}-F_{t}<0\right)$ stands for the increasing force.

Mean values (Fig. 4) and standard deviations (Fig. 5) were calculated for each time series in relation to the wind attack angle and mean wind speed. Figures 6, 7 and 8 were put down in order to analyze the wind structure influence on the forces in guys. Influence of mean wind speed profiles on the mean values and standard deviations of forces in guys at the mean wind speed of $v=10 \mathrm{~m} / \mathrm{s}$ at measured the height $70 \mathrm{~cm}$ can be observed at these graphs. a)

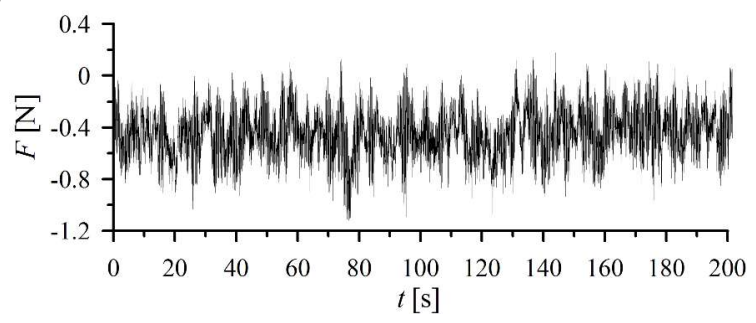

ग)

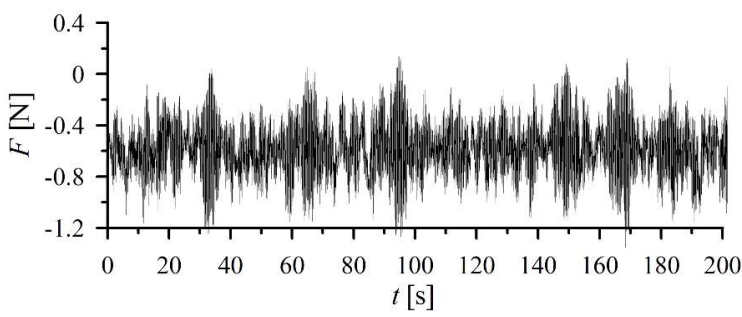

c)

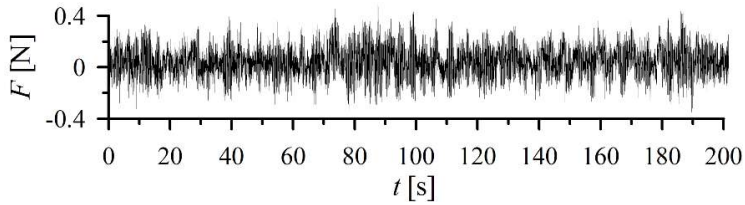

Fig. 3. Variation of forces in time for the lower guy of the square mast at the wind profile No. 3 at $v=10 \mathrm{~m} / \mathrm{s}$ for:

a) $\alpha=0^{\circ}$, b) $\alpha=45^{\circ}$, b) $\alpha=90^{\circ}$

a)

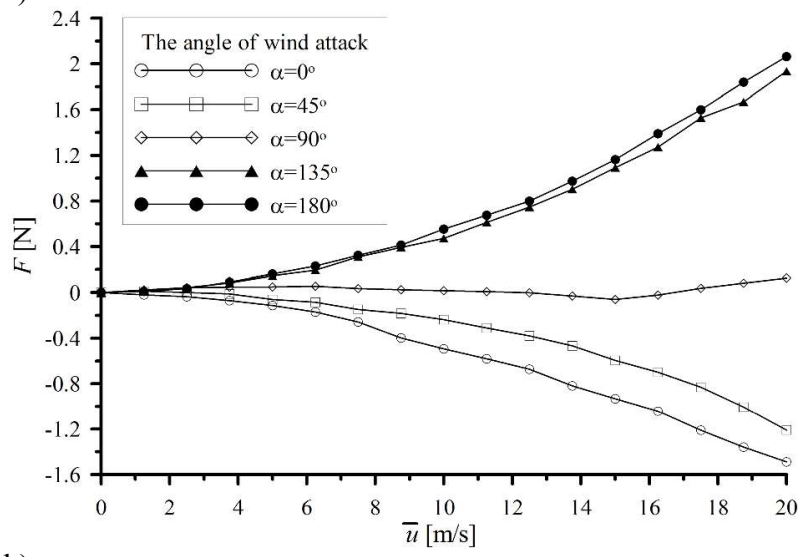

b)

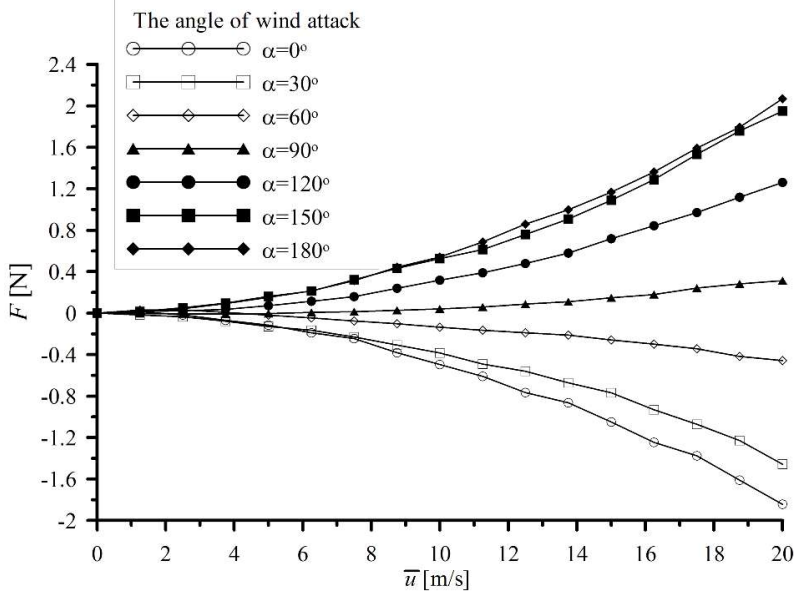

Fig. 4. Mean value of force $F$ for the lower guy at the wind profile No. 1 for : a) square mast, b) triangular mast. 
a)

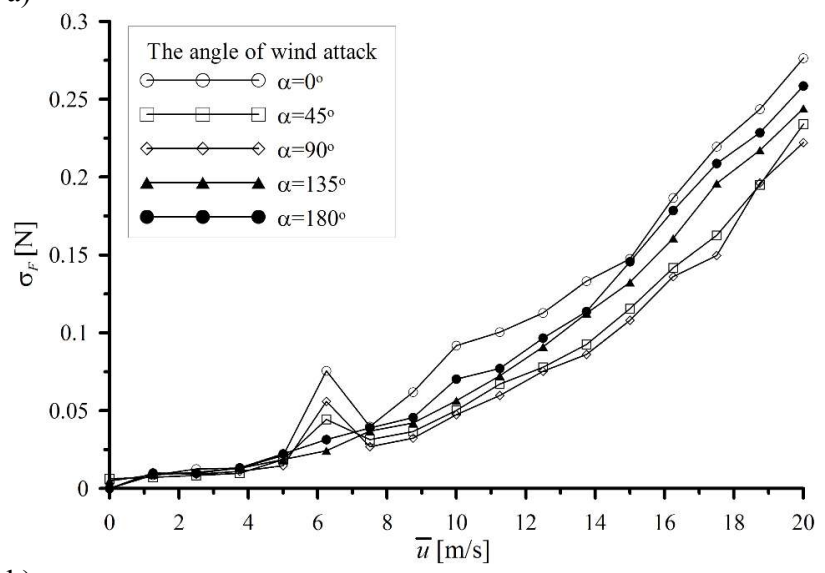

b)

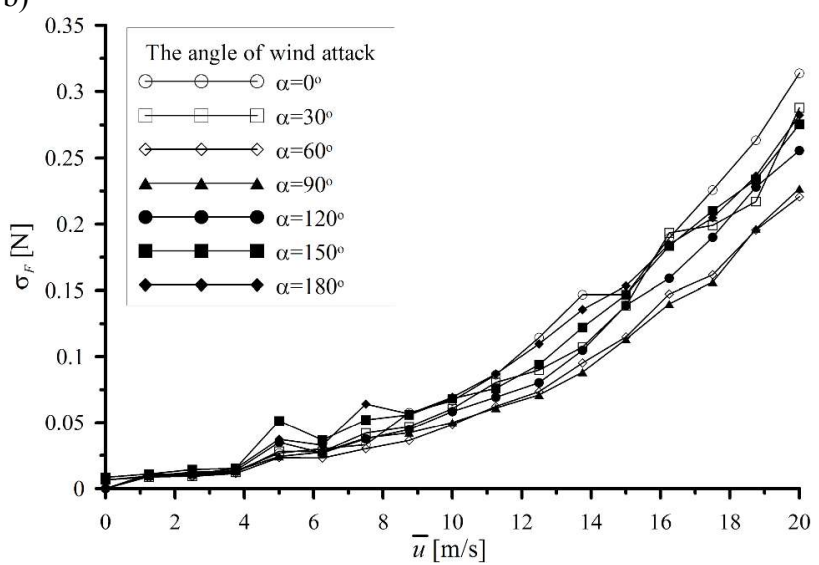

Fig. 5. Standard deviation $\sigma_{F}$ for the upper guy at the wind profile No. 1: a) square mast, b) triangular mast.

a)

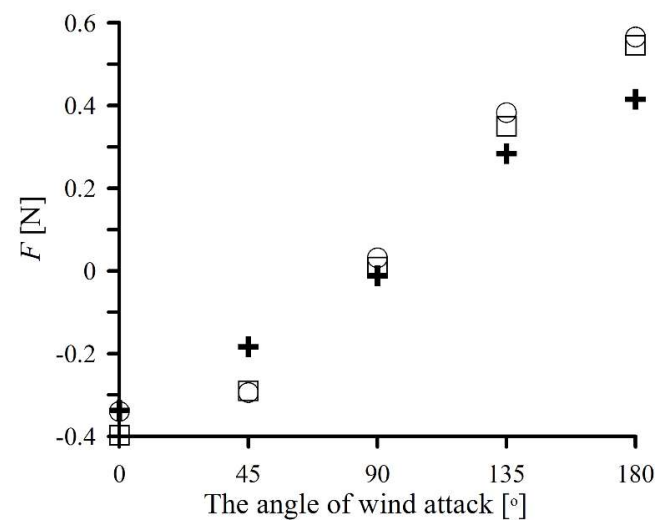

b)

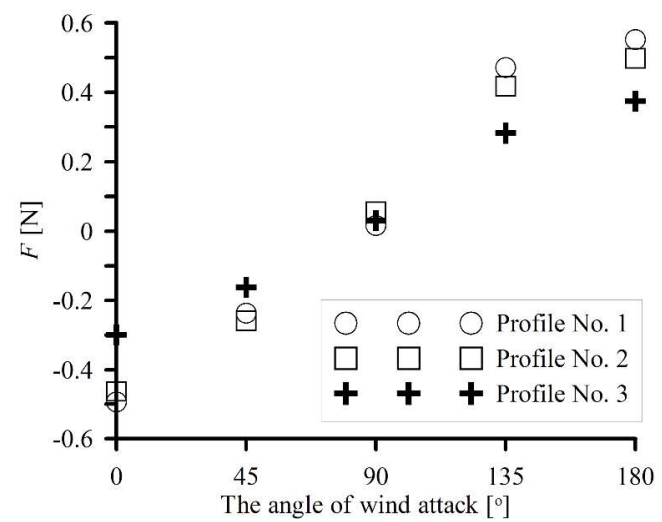

Fig. 6. Mean values of $F$ force for square mast at $v=10 \mathrm{~m} / \mathrm{s}$ at different angles of wind attack: a) upper level of guys, b) lower level of guys. a)

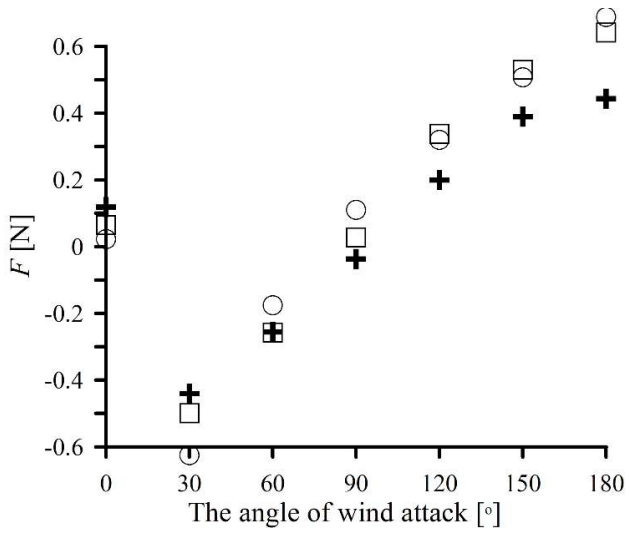

b)

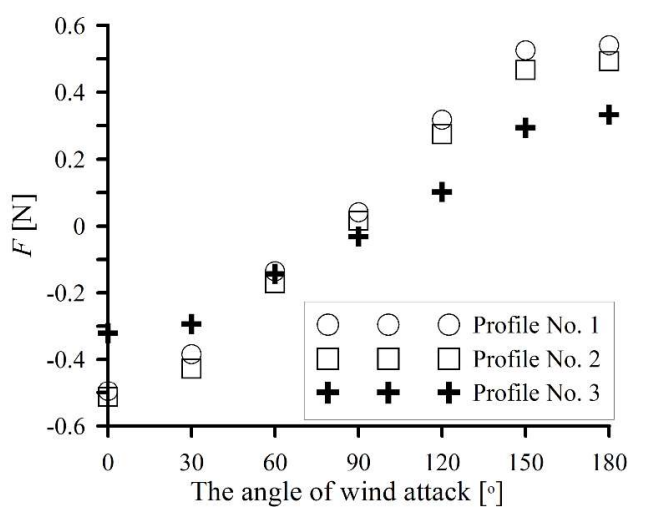

Fig. 7. Mean values of $F$ force for triangular mast at $v=10 \mathrm{~m} / \mathrm{s}$ at different angles of wind attack: a) upper level of guys, b) lower level of guys.

a)

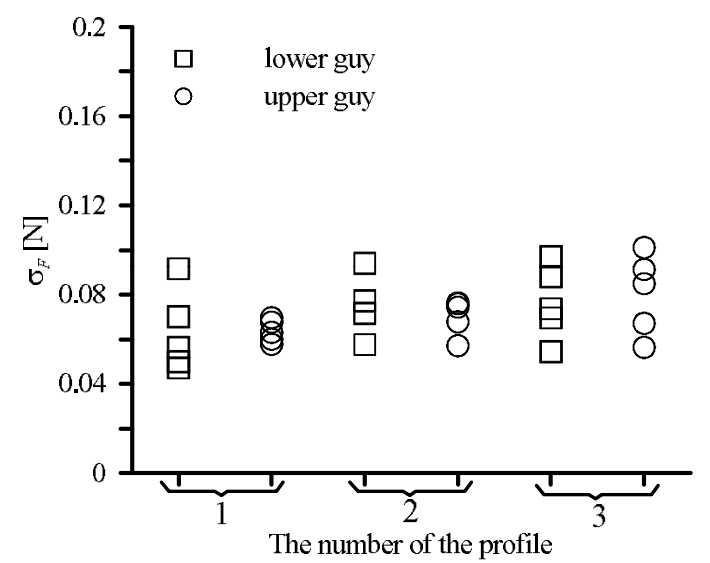

b)

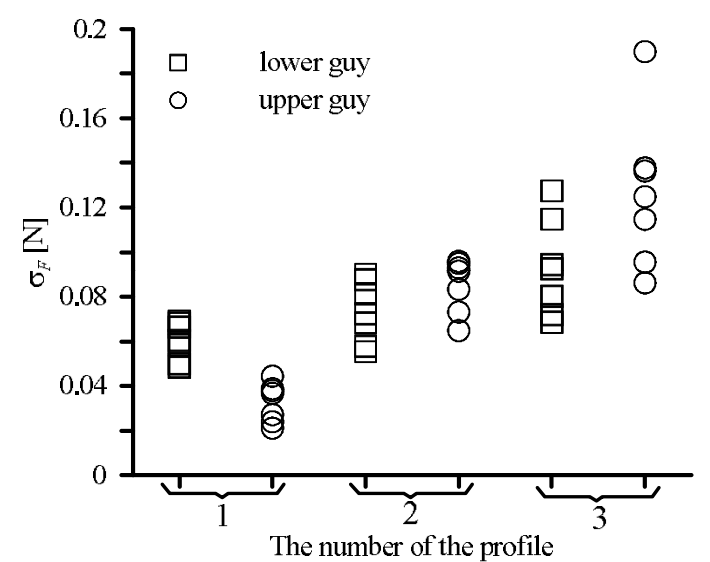

Fig. 8. Standard deviations of the axial force $\sigma_{F}$ in guys at $v=10 \mathrm{~m} / \mathrm{s}:$ a) square mast, b) triangular mast. 
Under the action of wind the forces in windward guys increase. If we rotate the mast, differences between forces $F_{o}$ and $F_{t}$ decrease until the guy is in the plane perpendicular to the direction of flow. At this setting the force is small in comparison to other positions. When the angle of wind attack $\alpha$ is greater than $90^{\circ}$ the difference between forces $F_{o}$ and $F_{t}$ is positive (force in the guy is smaller than the initial tension) and its value increases to achieve the biggest value at $\alpha=180^{\circ}$.

There are peaks of standard deviations noticeable at the graphs in Fig. 5 at some mean values of wind speeds. They are more evident at higher numbers of wind profiles, which means higher values of turbulence. The peaks are observed in graphs referring to all guys of mast, nevertheless if the guys are located in the planes along or across the mean wind. This means that the top of the mast is moving in both directions. This last conclusion means that the force variation is generated by the vibration of the mast shaft, rather than the vibrations of guys only. Increasing vibration amplitudes which follow the increase in turbulence means that the mast vibrations are caused by buffeting.

There are changes of guy forces at different wind profiles shown in Figures 6 and 7. It can be noticed, that the higher number of the wind profile and higher turbulence intensity give smaller changes in guy forces. The difference of forces in windward and leeward guys may reach even up-to $40 \%$.

The wind structure influences the standard deviations, as well. This can be seen in Fig. 8. In both cases of the square shaft cross-section, as well as the triangular one, the higher values of turbulence intensity generate higher values of standard deviations of guy forces. However, it is much more visible in case of the triangular shaft, than the square one.

\section{Conclusions}

The study shows that the structure of the wind has a great influence on the value of wind load on guys of masts. The differences in the mean values of normal forces in guys, exposed to the different wind profiles, are up to $40 \%$ for the lowest values of the force. The standard deviations for the normal forces also depend on the structure of the wind. The higher peak value at the abscissa in the graph of power spectral density produces greater maximum value of the standard deviation of the normal force. The study also shows that the values of forces in guys are mainly influenced by the work of the mast itself. There is much smaller influence on the axial forces of the wind forces applied directly to the guys. This is confirmed by the fact that if the guys are set in the plane perpendicular to the mean wind direction, axial forces are negligibly small when compared to ones obtained at other rotations.

In this study, there has been observed critical velocity, which produces mast vibrations and as the result, higher amplitudes of variation of axial forces in guys. This phenomenon requires further research mostly on the description of the origin of the critical velocity and the ways to avoid this occurring.

\section{References}

1. P. Harikrishna, A. Annadurai, S. Gomathinayaga m, N. Lakshmanan, Full scale measurements of the structural response of a $50 \mathrm{~m}$ guyed mast under wind loading, Engineering Structures 25 (2003) 859-867.

2. S. Fabre, M. Stickland, T. Scanlon, A. Oldroyd, D. Kindler, F. Quail, Measurement and simulation of the flow field around the FINO 3 triangular lattice meteorological mast, J. WindEng.Ind.Aerodyn.130 (2014) 99-107.

3. J. Bęc, T. Lipecki, E. Błazik-Borowa, Pomiary drgań aeroelastycznych modeli masztów $\mathrm{z}$ odciągami $\mathrm{w}$ tunelu aerodynamicznym, Budownictwo i Architektura 12 (1) (2013) 211-218 (in Polish)

4. J. Bęc, T. Lipecki, E. Błazik-Borowa, Research on wind structure in the wind tunnel of Wind Engineering Laboratory of Cracow University of Technology, Journal of Physics: Conference Series 318 (2011), doi: 10.1088/1742-6596/318/7/072003 